\title{
AN EXPERIMENTAL DETERMINATION OF THE SPEED OF MIGRATION OF SALMON IN THE COLUMBIA RIVER ${ }^{1}$
}

\author{
CHARLES WILSON GREENE
}

Professor of Physiology, University of Missontri

TWO FIGURES

Certain fishes, like some birds, carry out extensive migrations, but unlike birds, their movements are hidden from direct observation. Commercial fishermen dip their nets into the waters and learn to know many of the movements of fishes by the character of the catch. Certain fishes travel in great schools, and this tendency to herd together furnishes an easy method for following, especially those schools that swim near the surface. Presumably the migratory movement serves one of two purposes; either it is a means for providing food, or it brings fishes to the spawning ground.

The method of following the movement of fishes by the quantity of the catch is at best crude. One has no assurance that the school from which the catch is made in one locality at a given time is identical with that from which another catch is taken, even in approximately the same locality and at a nearly related time. For this reason it is almost imperative that one shall identify the individual fishes observed in order to determine their movements from one locality to another. Following this line of reasoning, Rutter $^{2}$ undertook to brand migrating Pacific salmon in the Sacremento River in 1902. This seems to have been the first effort at marking individual salmon with a view to determining their migrations in our North American waters.

1 Published by permission of the Commissioner of Fish and Fisheries.

2 Rutter: Bull.U.S. Bureau of Fisheries, 22, 122, 1902. 
The Pacific salmon is an unusually favorable fish upon which to determine the factors in migration. It has been known for a number of years that these fishes spawn in the cold waters of fresh water streams, usually in the mountains. The eggs are hatched and the young are developed to the fingerling stage and then migrate down the rivers to the sea. In the sea they feed a number of years until maturity. When maturity is reached they reënter the estuaries of the rivers, ascend the rivers to spawning grounds and deposit their eggs. In the case of all the species of the genus Oncorhynchus the fishes die after they once spawn. They do not again return to the salt waters of the ocean.

When a salmon once enters the fresh water rivers, it, seemingly, makes a pretty direct run to the spawning grounds. This run often extends over several hundred miles and may consume as much as two or three months of time. When the fish enter the rivers they are in the very finest physical condition. Their muscles are developed apparently to the fullest extent and their tissues as a whole are loaded with nutritive material, i.e., fat. This is the result of the long months of feeding during the life in the ocean. Apparently the ocean furnishes rich feeding grounds and is visited for the distinct purpose of supplying a more favorable condition of nutrition. When the fish enter the fresh waters for their long journey they stop feeding absolutely, a fact that is well known for the Atlantic salmon from the work of Miescher and of Noel Paton. These facts in the case of the Pacific salmon have been determined by the observations of numerous investigators of the United States Bureau of Fisheries. Rutter particularly has shown that the salmon not only does not eat but that the digestive tract diminishes sharply in size during this fasting period. I have confirmed Rutter's work for both the Sacramento and the Columbia River regions.

This migration of salmon in fresh water is a period of strong activity. The fishes make their way up the streams against strong rapids and sharp water falls. Before passing the latter obstructions salmon will ofttimes leap the falls in many unsuccessful attempts, even jumping to the extent of six or seven feet in height and against the known swiftness of the water under such condi- 
tions. This tremendous output of energy can only take place at the expense of nutritive substance on hand when the journey is begun.

A still more fundamental process is occurring during the migration, namely, the rapid development of the reproductive tissues. When the salmon enter the mouths of the rivers, especially earlier in the season, the reproductive organs are very small in size and immature in development. As the journey progresses the reproductive organs in both sexes grow rapidly and the reproductive cells approach maturity of form and structure. This growth of new tissue in the absence of an income of food represents a remarkable physiological process. Such growth can take place only at the expense of materials on hand, and to produce new tissues requires substances more complex than the mere fats, which might possibly account for the production of the energy of motion. We have, therefore, in this animal two lines of physiologicalactivity which lend peculiar interest to the subject of nutrition in the absence of food, namely, first, the source of the dynamic energy expended by the animals, and second, the source and character of the nutritional changes which result from the development of a special set of organs at the expense of other portions of the body. It is obvious that the question of the rapidity and of the intensity of the energy changes in these processes are the all-important factors. In order to secure information which would help to elucidate those factors, it became necessary to determine as accurately as possible the details of the migration of salmon. It seemed desirable to determine the speed of the migration, the total time consumed by the fish in the journey, and the detailed character of the migration, all with a view to determining the intensity of the energy put forth in making the journey.

In order to subject the questions at issue to a test, I arranged a marking experiment on fish secured in the lower Columbia River. It seemed that the only way to get accurate information would be to mark individual fishes in such a way as to be absolutely certain of their identification. My plan was to secure the live fishes, mark them with metal tags and turn them loose in the river again with the hope that they would be re-taken. The numerous com- 
mercial fishery interests in the lower Columbia River gave abundant opportunity for the recapture of individual fishes, notwithstanding the broad expanse of territory necessary to be covered. Rutter marked his fish on the Sacramento River by a method of branding with a hot iron, similar to that used for marking cattle on the plains in early days. Of some 150 fish branded by him, only three were afterwards re-taken an the Government Fisheries in the lower head water of the river.

On August 4, 1908, I secured and marked with metal tags 59 fish. These were immediately liberated in the river in good condition and in each case quickly swam out of sight. The fish were secured through the kindness of Superintendent Nicholay Hansen of the Chinook, Washington, Fish Hatching Station. Superintendent Hansen generously furnished transportation and facilities for taking and marking the fish. The fish were taken from the Washington State Trap which is located just above Sand Island about eight miles from the mouth of the Columbia River. This location was peculiarly favorable to the execution of the experiment. In the first place the spot is well within the mouth of the river, so that the average salinity of the water is only mildly brackish. It is also on the border land between the two great fishing fields utilized by the traps on the one hand and the gill nets on the other, thus giving the liberated fish a fair chance for a successful run. The location promised opportunity for determining whether or not the fish might migrate back and forth through the estuary with the ebb and flow of the tides, since Rutter has advanced the theoretical view that such is the case. The later details will show that the location was especially fortunate with reference to this particular point. The salmon were run from the trap into a large live car used by the station. Theywere marked one by one from this car.

The apparatus adopted for marking the fish in this experiment was the aluminum ,metal stock marking button used for marking domestic animals, - sheep and cattle. The button is adapted for insertion in the ear of sheep or other animals and can be riveted together in a way that makes it absolutely impossible to break it apart except by actually tearing it from its location. The 
aluminum is light and furnishes sufficient surface for the stamping of numbers, initials, or other matters of identification. The tag was made of two pieces on the general principle of a Yankee button. The first piece consisted of a circular disc forged on to a hollow shaft some $7 \mathrm{~mm}$. in diameter. The disc of this piece had a serial number stamped upon it. The second piece was similar to the first except that the disc was forged on a solid rod or rivet. The disc of this piece carried the legend "U.S. Fish." When the rivet of the second piece was inserted into the shaft of the first piece and compressed, the aluminum filled the cavity so as to make it impossible to separate the two.

\section{THE DETAILS OF THE MARKING}

The salmon is a gamey fish. When taken in a dip net it struggles violently to escape. By skillful management a salmon can be held just under the surface of the water in such a way that its struggles will produce marked fatigue. When a fish is thus fatigued it will remain quiet for some seconds. In this work advantage was taken of that fact and the instant the salmon stopped struggling it was lifted out of the water, grasped by the base of the tail, swung free of the net, and laid gently on the measuring board. In this position the tip of the nose was brought up against the vertical end of the measuring apparatus, and the length read off and announced to the recorder. The next step was to attach the marking button. This was done by puncturing a hole in the caudal fin into which the button was inserted and riveted. The whole process required less time than it takes to describe it.

The salmon stood the handling very well. They were immediately released overboard in the direction of open water. If there was the slightest question as to asphyxia, the fishes were first released back into the car and later, when they had fully recovered, were turned into open water. The fishes of this series came through in exceptionally good condition. 


\section{A DISCUSSION OF THE INJURY INFLICTED IN THE MARKING PROCESS}

No physical injury is imposed upon the fishes up to the point where the $7 \mathrm{~mm}$. hole is punched in the tail for the insertion of the marking button. This injury is relatively insignificant. True it produces a transient stimulus to the skin which leads to physiological reflexes for the moment. If the button is carelessly inserted so as to continually compress the tissue of the caudal fin, this may lead to further stimulation of a certain degree.

A factor of far more importance than the direct physical injury is the possible asphyxiation that results during the handling of the fish in air. When a fish is taken out of the water, the water quickly drains from the mouth cavity and from over the gills, thus exposing the latter to air. When the air comes in free contact with the gill filaments, even better aëration may occur than when the fish is in water. The trouble comes when the gill filaments no longer supported by water adhere together in a mass. Under these conditions asphyxiation takes place rapidly. The anatomical arrangements of the gillcovers and gills in different species are, for the above reasons, largely responsible for variations in the rapidity with which asphyxiation occurs. In the salmon one cannot but note the endurance of the fish against asphyxiation and the ease with which this condition may be removed by artificial respiration. A fish can endure a considerable degree of asphyxiation without any notable evil effects unless that degree be carried to the point which results in loss of function to the respiratory center.

\section{A DISCUSSION OF THE INFLUENCE OF HANDI ING ON THE MIGRATION OF THE SAIMON}

A most important question that arises in this experiment is this: What effect will the handling have on the future course of migration, and the manifestation of the migratory instincts in the salmon? It will have little effect for the following reasons: 
Recently Edinger ${ }^{3}$ has called attention to the fact that the low form of the brain of the lower vertebrates must be taken into consideration in judging the reactions of such animals to stimuli. The salmon, for example, should be considered in view of its biological position in the animal series. Its brain is very simple in type. The cerebral lobes are small and the cortical structures of relatively slight complexity. If the salmon possesses any association tracts they are very simple. Such a low form of brain cannot execute very complex reactions. There is not the necessary anatomical machinery. The brain and spinal cord are capable of carrying on only the usual reflexes of muscular movement, circulation, respiration, etc. It is to be assumed that the injury to the skin, as for example punching the hole through the tail for the marking button, leads to little more than the reflex of muscular movements. As a matter of fact direct observation shows that these muscular responses are relatively slight, and include little more than the motions of swimming. There is in addition a transient inhibition of the respiratory movements. Judging from the results of other experiments, one may assume that there will be some slight disturbance in the coördination of the circulatory apparatus. These more or less complicated reflexes disappear within a few minutes at most.

Those conditions which lead to the migration of salmon are the chief directive stimuli at the migration time. They supercede all other stimuli. In comparison with them the effects of transient stimuli, such as cutaneous lesions, etc., are insignificant. Large numbers of fish taken in the upper waters of the Columbia River are injured in one way or another. Some of them have received lacerations many fold greater than that inflicted upon the fish for the purposes of marking. Yet these fish are forging ahead toward the spawning grounds with apparently no digression.

${ }^{3}$ L. Edinger: Ueber das Hören der Fische und anderer niederer Vertebraten; Zentralb. f. Physiol., 22, 1, 1908. 


\section{A DISCUSSION OF THE RESULTS OF THE MARKING EXPERIMENT}

Three species of salmon are represented in the experiment. There were 25 Chinooks (Oncorhynchus tschawytscha), 16 silver salmon (0. kisutch), and 18 steelhead (Salmo gairdneri), 59 fish in all. These fish ranged in length from $41 \mathrm{~cm}$. to $103 \mathrm{~cm}$., and in weight up to thirty-five pounds, and were well distributed in size. Out of the total number liberated, 17 were reported caught again, and the marking buttons of 16 of these were recovered. Six of the recovered fishes were Chinooks, 6 silvers, and 5 steelhead. The general facts of the experiment are assembled in table 1.

The aluminum metal of the marking buttons proved to be of special value in an unexpected way. Aluminum is strongly corroded in salt water, and not affected in fresh water. This serves to give an index on the career of the fish in salt and brackish water. The strong corrosion which appeared on some of the marking buttons is positive proof of the return of the fish to salt water after they were marked. The degree of corrosion cannot be taken as an estimate of the relative time spent in concentrated as against relatively dilute sea-water. In other words a given corrosion may mean a long sojourn in slightly brackish water, or a shorter sojourn in relatively pure sea-water. But in certain specimens, as for example number 80 which was out only eleven days until caught again, it is safe to assume that the fish spent most of the time in relatively undiluted sea-water.

Two of the Chinook salmon, numbers 80 and 123, were re-taken after eleven and thirty-one days respectively. Number 80 was taken fifteen miles up the river from the point liberated, a distance requiring not over two days' time for a straight run. This fish had at least nine days in which its movements are unaccounted for. The history of the nine days is represented in the extensive corrosion on one face of the aluminum button. This will be readily seen from the photographs represented in figs. 1,2. So great a corrosion in so short a time indicates a relatively concentrated sea-water. In all probability this fish swam towards the ocean well out toward or beyond the jetty, and the average of its time 
THE SPEED OF MIGRATION OF SALMON

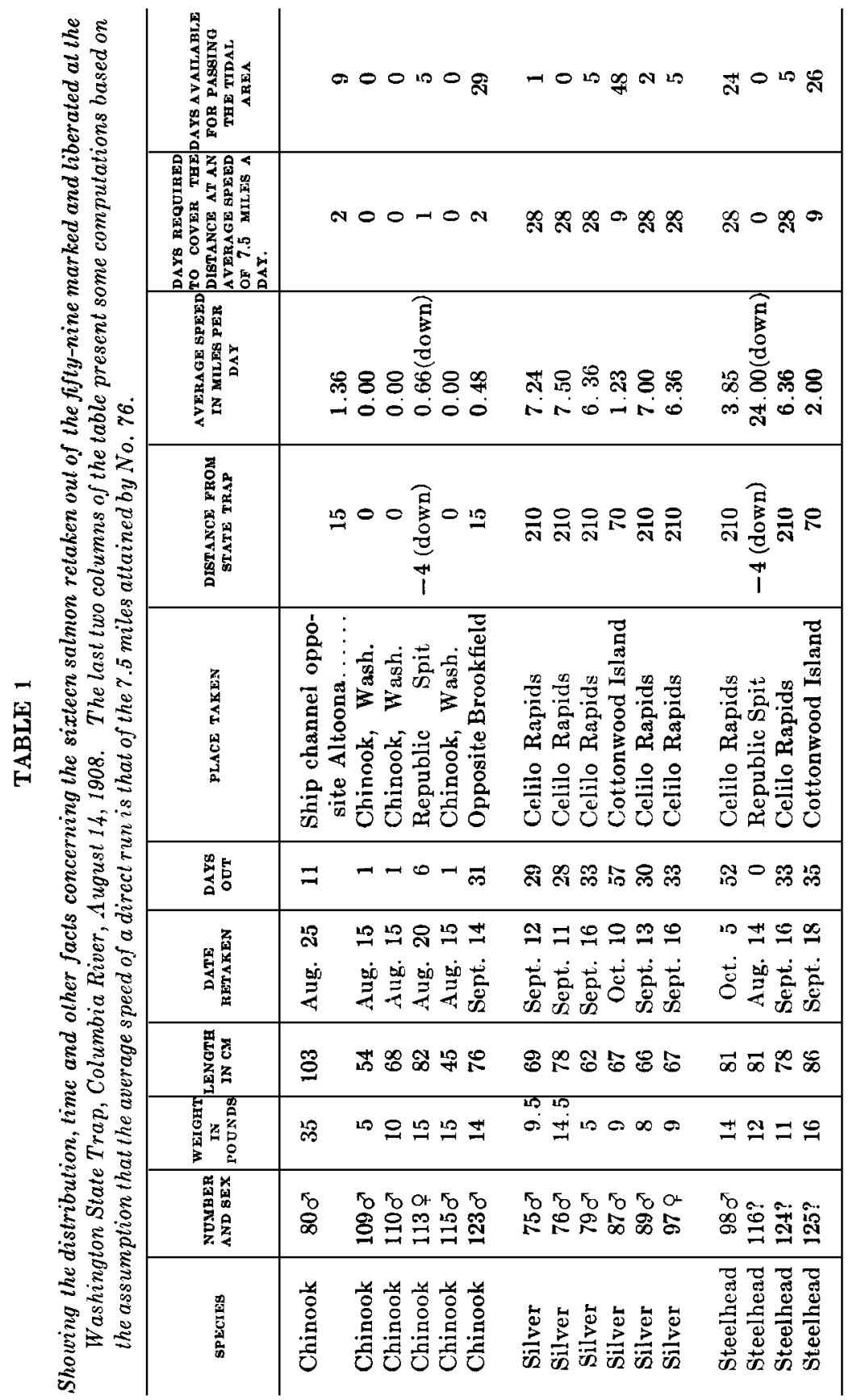




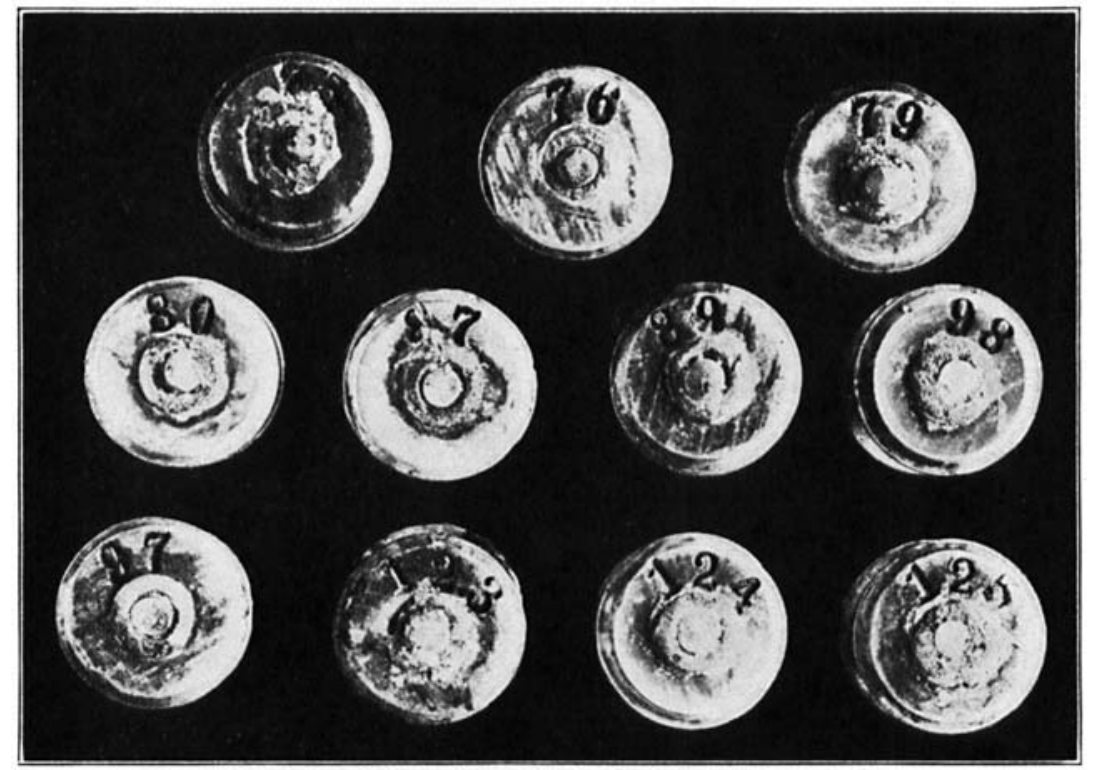

Fig. 1 Photograph showing the corrosion of the aluminum marking buttons recovered from the marked fishes. The tags are not included for the fishes retaken within a few days.

was spent in water as salty as that represented by the region of Canby Light.

Chinook number 123 was out thirty-one days and traveled up stream a distance of only fifteen miles, requiring two days for the journey. Its button was the second deepest corroded of the series. The corrosion is evidence that its bearer spent much if not most of the time below the point in the river where it was liberated. This evidence is second in importance only to actual capture of the fish below the region.

One Chinook, number 113, was recaptured, six miles down the river from the point of liberation. As it was out only six days no corrosion occurred.

The silver salmon made the longest runs, five of the six specimens re-taken having traveled a distance of two hundred and ten miles. Three of the five fishes, numbers 76,89 and 97 , each bore 


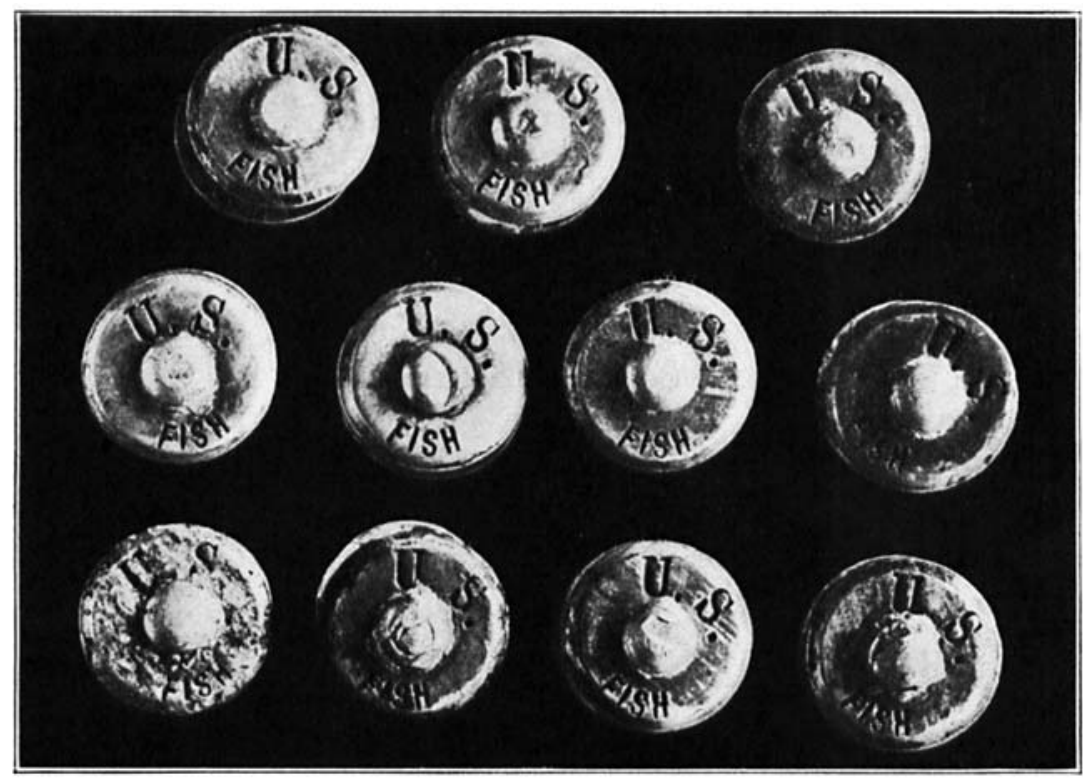

Fig. 2 Photograph showing the obverse faces of the aluminum buttons pictured in fig. 1 The order of arrangement is the same in the two pictures.

marking buttons that were extensively corroded. These fish made the entire journey at an average speed of from 6.36 to 7.50 miles per day. On the basis of the evidence that corrosion furnishes, these individuals must have spent some time in brackish or salt water.

Silver salmon numbers 79 and 75 bore buttons that were in the first case not corroded, and in the second only slightly corroded on one side. From the line of evidence which has been given consideration one must infer that these fish did not spend much time at or below the point where they were liberated.

Silver salmon number 87 is a decided exception in the list. This fish was re-taken only seventy miles up the river, yet it was out a total of fifty-seven days. The marking button does not present evidence of long contact with sea-water. It is slightly corroded on one surface but not more than would occur in slightly brackish water. 
Of the 18 steelhead that were marked and liberated 5 were re-taken. Number 116 was caught four miles down the river about four hours after it was liberated. The remaining steelhead were caught, one in the region of the point liberated, one seventy miles up the river, and two were re-taken two-hundred and ten miles up the river. Of the last two, one, number 124, was out thirty-three days and bore a button that showed only slight corrosion. The other, number 98, was out fifty-two days and its button showed marked corrosion. Evidently the former spent little time in brackish water, while the marking button of the latter indicates a long contact with sea-water. The steelhead number 125, taken seventy miles up the river after thirtyfive days, shows a history of contact with salt water similar to that of number 98.

\section{THE AVERAGE SPEED OF MIGRATION}

This experiment was launched in tide water. Hence the speed of migration is influenced by the factor of acclimatization of the sea run salmon to fresh water. Undoubtedly a very much higher speed is attained in fresh water than is accomplished in making the journey through the tidal region. A number of instances have been given to show that the fishes spent much time in the brackish water after their marking. It is safe to assume that salmon travel at a fairly uniform speed in fresh water when different individuals are compared under similar conditions. Inspection of table 1 suffices to show that either the assumption is untenable or that a number of the salmon have not made direct runs up the river. Undoubtedly the latter represents the facts in the case, and the corrosion of the marking buttons is corroborative proof. If the speed of the fishes is supposed to be uniform through the group and is computed on the basis of the average made by those representing the highest in the list, then, as table 1 shows, there will be for each fish, a number of days unaccounted for. In some cases, numbers $98,125,123$ and 87 the unaccounted for days amount to $24,26,29$ and 48 days respectively. These are the days which represent the period of adjustment of the 
fish when it passes from the sea-water to the fresh water at the mouth of the river.

Rutter ${ }^{4}$ has advanced the theory that the salmon makes the journey through tide water by running up stream during the ebb, and down stream during the flood tide, that is, the fish stems the current during the flow of each tide. Rutter arrived at this conclusion by following the variations in the catch of the fisheries at the different towns along the San Francisco Bay and Lower Sacramento River. The theories of Rutter explain in part the movement of salmon in tide water, but tidal currents are not sufficient alone to account for the movements. A much more important factor is the condition of water as regards the content of salt. Salmon are delicately responsive to stimulation by the variation in the degree of admixture of sea-water and fresh water in the tidal area.

The present observations show a very much longer time spent by salmon in the tidal waters of the Columbia River than that deduced by Rutter for the Sacramento River. It is safe to conclude that the salmon spend not less than thirty to forty days in passing the tidal area of the lower Columbia River. When once through the tidal area they make the journey up the river at an average speed of not less than seven and one-half miles a day.

Autter: Bull. U. S. Bureau of Fisheries, 22, 122, 1902. 